\title{
LUT
}

Lappeenranta

University of Technology

\section{Anchoring lead-free halide Cs3Bi2I9 perovskite on UV100-TiO2 for enhanced photocatalytic performance}

Bresolin Bianca-Maria, Balayeva Narmina, Granone Luis, Dillert Ralf, Bahnemann Detlef, Sillanpää Mika

This is a Post-print version of a publication

published by Elsevier

in Solar Energy Materials and Solar Cells

DOI: $\quad 10.1016 /$ j.solmat.2019.110214

Copyright of the original publication: (c) 2019 Elsevier B.V.

Please cite the publication as follows:

Bresolin B., Balayeva N., Granone L., Dillert R., Bahnemann D. Sillanpää M. (2020). Anchoring lead-free halide Cs3Bi219 perovskite on UV100-TiO2 for enhanced photocatalytic performance. Solar Energy Materials and Solar Cells, Vol 204. DOI: 10.1016/j.solmat.2019.110214 


\title{
Anchoring lead-free halide $\mathrm{Cs}_{3} \mathrm{Bi}_{2} \mathrm{I}_{9}$ Perovskite on UV100-TiO \\ for enhanced photocatalytic performance
}

\author{
Bianca-Maria Bresolin ${ }^{a^{*}}$, Narmina O. Balayeva ${ }^{b}$, Luis I. Granone ${ }^{\mathrm{b}, \mathrm{c}}$, Ralf Dillert ${ }^{\mathrm{b}, \mathrm{c}}$, \\ Detlef W. Bahnemann ${ }^{\mathrm{b}, c, d}$, Mika Sillanpääa,e
}

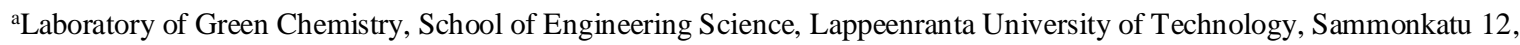
50130 Mikkeli, Finland.

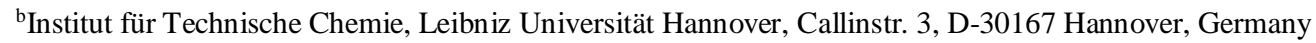
${ }^{c}$ Laboratory of Nano- and Quantum-Engineering (LNQE), Gottfried Wilhelm Leibniz University Hannover, Schneiderberg 39 , D-30167 Hannover, Germany.

¿Laboratory “Photoactive Nanocomposite Materials”, Saint-Petersburg State University, Ulyanovskaya str. 1, Peterhof, 198504 Saint-Petersburg, Russia

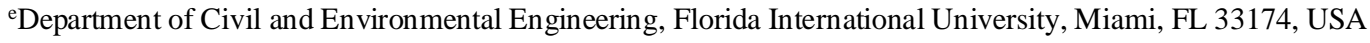

\begin{abstract}
Halide perovskites have shown great potential in photocatalytic applications. In order to enhance the charge transportation efficiency, the chemical stability, and the light absorption ability, we anchored a lead-free halide perovskite $\left(\mathrm{Cs}_{3} \mathrm{Bi}_{2} \mathrm{I}_{9}\right)$ on $\mathrm{UV100}-\mathrm{TiO}_{2}$ nanoparticles to build a visiblelight active photocatalysts. The as-prepared material exhibited excellent stability and a remarkable yield for photocatalytic oxidation of methanol to formaldehyde under visible light irradiation. The photocatalyst was characterized using X-ray diffraction, scanning electron microscopy, energydispersive X-ray spectroscopy, Transmission electron microscopy, X-ray photoelectron spectroscopy, ultraviolet-visible diffuse reflectance spectroscopy, Brunauer-Emmett-Teller surface area measurement, and photoelectrochemical properties. The analyses confirmed a remarkable improvement of visible-light absorption, a favorable decrease in the recombination of photoinduced charge carriers, and a suitable bandgap for visible-light photocatalytic applications.
\end{abstract}


Recycle experiments showed that the composites still presented significant photocatalytic activity after three successive cycles. A possible underlying mechanism of the composite accounting for the enhanced photocatalytic activity under visible light irradiation was proposed.

Our study aims to open new possibilities of using lead-free halide perovskites for photocatalytic applications.

\section{Keywords}

\section{Photocatalysis, Heterostructure, Perovskite, Titanium dioxide, Visible light}

*Corresponding author at: Laboratory of Green Chemistry, School of Engineering Science, Lappeenranta University of Technology, Sammonkatu 12, 50130 Mikkeli, Finland. E-mail address:Biancabresolin@yahoo, Bianca-maria.Bresolin@lut.fi. 


\section{INTRODUCTION}

Environmental pollution and energy demand are without any doubts among the biggest challenges of the new century $[1,2]$. In recent years, it has been reported a steady increase of water pollution in many parts of the world caused by the accelerated release of pollutants due to the combination of a growing population and a rapid industrial development [3-6]. Moreover, efficient and sustainable technologies for remediation of wastewater remain a current issue and great challenge for scientists [7]. On the other hand, it is equally urgent to find a renewable energy resource to answer the increasing energy demand and mitigate the negative effect of global warming [8-11]. Therefore, the development of highly efficient and eco-friendly methods for wastewater treatment based on renewable energy sources has become an imperative task.

Among different technologies, photocatalysis appears to be a promising way to solve simultaneous environmental and energy issues [12-15]. The initiating event in photocatalysis is the absorption of the radiation emitted by the sun and the formation of electron-hole pairs in the empty conduction band (CB) and the filled valence band (VB), respectively. To the extent that not all the electrons and holes after recombine, some of them may attenuate to the surface reacting with bounded groups, water or absorbed molecules. Generally, highly reactive oxygen species (ROS) are formed by interfacial transfer of electrons and holes to oxygen molecules dissolved in water and water adsorbed on the catalyst surface $[16,17]$. The strong oxidizing power of ROS induces the degradation and mineralization of many organic and inorganic wastewater pollutants $[18,19]$. As a sustainable technology, a photocatalytic process can operate at room temperature utilizing clean and renewable solar light as driving force for the abatement of contaminants with any production of hazardous residues after complete mineralization [20]. Among the studied photocatalysts, $\mathrm{TiO}_{2}$ is definitively the most investigated material due to its high oxidative efficiency, chemical stability, 
nontoxicity, and low-cost [21-23]. Unfortunately, the photocatalytic efficiency of $\mathrm{TiO}_{2}$ is still low, mainly due to the slow reactions and the low solar energy absorption capacity [24,25]. Charge generation and separation process are one of the factors that affect reaction rate employing $\mathrm{TiO}_{2}$ as a photocatalyst because the recombination process is usually found to be much faster than the interfacial charge carrier transfer [26,27]. Moreover, $\mathrm{TiO}_{2}$ exhibits a wide bandgap and thus it can only be excited by photons with wavelengths in the UV range, which accounts for around $5 \%$ of the solar radiation energy [28]. Therefore, enhancing the efficiency of the photocatalytic process and extending the light absorption range of $\mathrm{TiO}_{2}$ represent a current challenge for researchers.

In our research, we studied the formation of semiconductor heterostructures with improved electron dynamics and enhanced light absorption ability. In recent years, significant advances have been made to design various kinds of semiconductor-based heterostructures for many potential applications such as biomedicine, nanodevices, and photocatalysis [29,30]. In the past decades, semiconductor heterostructures have been extensively studied for their ability to enhance the photo-induced charge separation efficiency [31,32]. In general, a type-II heterojunction is formed when both the VB and the $\mathrm{CB}$ energetic positions are more positive or more negative in one of the semiconductors. In this case, the band bending may induce the photogenerated charges carriers to migrate from one semiconductor to the other resulting in a spatial separation of the electrons and holes on different sides of the heterojunction. This mechanism highly reduces the recombination rate of the charge carriers enhancing the charge separation efficiency, increasing the carrier lifetime, and consequentially improving the photocatalytic efficiency [33-36]. Moreover, by coupling a UV-active semiconductor, such as $\mathrm{TiO}_{2}$, with a visible light-active semiconductor, the synergic absorption ability of the two semiconductors extends the light response range improving the solar energy utilization [37]. 
Furthermore, among important technological developments of the current decade, perovskite material has achieved outstanding performances showing high power conversion efficiency, especially in photovoltaic applications [38-41]. In particular, organic-inorganic hybrid halide perovskites (HOIP) have become promising candidates due to their remarkable properties $[42,43]$. Unfortunately, the ambient instability and the easy decomposition of the labile organic components should be overcome in order to develop HOIP materials for environmental remediation. Moreover, the most efficient HOIPs usually contain lead, being a serious toxic disadvantage that limits commercial applications. On the other hand, among the inorganic perovskites, Bi-based halide perovskites have gained much attention solving the stability and toxicity issues related to leadbased perovskite materials $[44,41,45]$. In particular, cesium bismuth iodide $\left(\mathrm{Cs}_{3} \mathrm{Bi}_{2} \mathrm{I}_{9}\right)$ is new low toxicity and air-stable compound belonging to the perovskite family that exhibits remarkable and promising qualities. $\mathrm{Cs}_{3} \mathrm{Bi}_{2} \mathrm{I}_{9}$ is characterized by a dark cherry red color, and it can be easily synthesized at low temperature. Although the phase transitions of these compounds have been well studied [46-48], the optoelectronic properties of the ternary inorganic bismuth halides have not been explored extensively [41]. $\mathrm{Cs}_{3} \mathrm{Bi}_{2} \mathrm{I}_{9}$ has been reported to have bandgap energy of about $2 \mathrm{eV}$. Due to its narrow bandgap, it has a wide range of optical absorption, and it can be assumed to be suitable for applications in photocatalysis [49-51].

In our research, $\mathrm{Cs}_{3} \mathrm{Bi}_{2} \mathrm{I}_{9}$ perovskite and anatase $\mathrm{TiO}_{2}$ as new heterostructure material was coupled to improve the performance in photocatalytic applications. In particular, joining a wider bandgap semiconductor having a more positive conduction band edge potential (vs. RHE) to form a heterojunction structure may be a way to allow the inhibition of recombination of electron-hole pairs. On the other hand, the presence of $\mathrm{Cs}_{3} \mathrm{Bi}_{2} \mathrm{I}_{9}$ inorganic perovskite was addressed to improve the light absorption capacity of $\mathrm{TiO}_{2}$ and further enhance its photocatalytic activity. To our 
knowledge, this is the first report that employed UV100:Cs ${ }_{3} \mathrm{Bi}_{2} \mathrm{I}_{9}$ composites for photocatalytic water treatment.

\section{MATERIALS AND METHODS}

\subsection{Materials}

$\mathrm{TiO}_{2}$ Hombikat UV100 powder $\left(250 \mathrm{~m}^{2} \mathrm{~g}^{-1}\right.$ specific surface area, particle size $\sim 10 \mathrm{~nm}$ [52] $)$ was kindly provided by Sachtleben Chemie GmbH (now Venator Germany GmbH, Germany). Cesium iodide CsI (99.9\%, trace metals basis), bismuth iodide $\mathrm{BiI}_{3}$ (99\%), diethyl ether (99.8\%), and dimethylformamide (DMF, anhydrous, 99.8\%) were purchased from Sigma-Aldrich and used without further purification.

\subsection{Photocatalyst synthesis}

Perovskite $\mathrm{Cs}_{3} \mathrm{Bi}_{2} \mathrm{I}_{9}$ was synthesized from $\mathrm{CsI}$ and $\mathrm{BiI}_{3}$ using DMF as a solvent. In a typical synthesis, CsI and $\mathrm{BiI}_{3}$ were mixed in DMF $(20 \mathrm{~mL})$ in a molar ratio of $3: 2$, at $60{ }^{\circ} \mathrm{C}$ under continuous stirring overnight. After the complete evaporation of DMF, the material was washed three times with diethyl ether to remove any DMF residue and dried [53]. The $\mathrm{Cs}_{3} \mathrm{Bi}_{2} \mathrm{I}_{9}: \mathrm{TiO}_{2}$ composites were synthesized following a simple impregnation method. $\mathrm{TiO}_{2}$ and $\mathrm{Cs}_{3} \mathrm{Bi}_{2} \mathrm{I}_{9}$ were suspended in deionized water (Milli-Q, 18.2 M $\Omega \mathrm{cm}$ ) and sonicated for one hour. The suspension was centrifuged three times with deionized water and the obtained solid was subsequently calcined (400 ${ }^{\circ} \mathrm{C}$ ) to form the $\mathrm{Cs}_{3} \mathrm{Bi}_{2} \mathrm{I}_{9}: \mathrm{TiO}_{2}$ composites. The obtained materials were finally ground into fine powders. The schematic illustration of the multi-step preparation pathway is presented in Figure 1. The four synthesized composites with different weight ratios were named as UV1000.05, UV100-0.1, UV100-0.25, UV100-0.5, where the numbers demonstrate the weight percentage of $\mathrm{Cs}_{3} \mathrm{Bi}_{2} \mathrm{I}_{9}$ in respect to $\mathrm{TiO}_{2}$ (Table $\mathbf{1}$ ). 


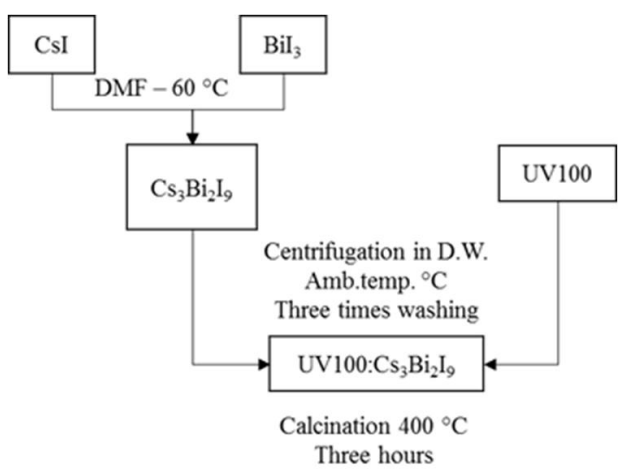

Figure 1: Schematic illustration of the preparation pathway of the $\mathrm{Cs}_{3} \mathrm{Bi}_{2} \mathrm{I}_{9}: \mathrm{TiO}_{2}$ composites.

Table 1: List of synthesized materials

\begin{tabular}{c|c} 
Name of material & $\mathrm{Cs}_{3} \mathrm{Bi}_{2} \mathrm{I}_{\mathbf{9}} \mathbf{w t} \%$ \\
\hline $\mathbf{C s}_{\mathbf{3}} \mathrm{Bi}_{2} \mathrm{I}_{\mathbf{9}}$ & - \\
$\mathbf{U V 1 0 0 - 0 . 5}$ & 0.50 \\
$\mathbf{U V 1 0 0 - 0 . 2 5}$ & 0.25 \\
$\mathbf{U V 1 0 0 - 0 . 1}$ & 0.10 \\
$\mathbf{U V 1 0 0 - 0 . 0 5}$ & 0.05 \\
$\mathbf{U V 1 0 0}$ & -
\end{tabular}

\subsection{Photocatalyst characterization}

The crystal phases and lattice parameters of the samples were determined by powder X-ray diffraction using a D8 Advance diffractometer (Bruker) provided with a $\mathrm{Cu}$ Ka radiation source. Diffuse reflectance UV-Vis spectroscopy was employed using a spectrophotometer (Varian Spectrophotometer Cary-100 Bio, Agilent technologies). Barium sulfate was used as a standard for $100 \%$ reflection. For the bare perovskite, the bandgap was deduced from Tauc plot [54]. Brunauer-Emmett-Teller (BET) measurements were performed to determine the specific surface 
area of the precursors and the synthesized powders. The analysis was performed by a single-point measurement of physisorption of molecular nitrogen at $-196^{\circ} \mathrm{C}$ using a Chemisorb 2300 apparatus (Micromeritics Instrument). Information on the elemental composition and the chemical state of the species composing the sample surfaces were recorded using X-ray photoelectron spectroscopy (XPS-Leybold Heraeus) with $300 \mathrm{~W} \mathrm{Al} \mathrm{Ka} \mathrm{radiation.} \mathrm{The} \mathrm{morphology} \mathrm{of} \mathrm{the} \mathrm{materials} \mathrm{was} \mathrm{further}$ defined using scanning electron microscopy (SEM). Field emission scanning electron microscopy (FESEM) images were obtained in a Jeol JSM $6700 \mathrm{~F}$ microscopy at $2.0 \mathrm{kV}$ acceleration voltage. The elemental composition was determined by energy dispersive spectroscopy (EDS). Electrochemical measurements were performed in a three-electrode electrochemical cell provided with a Pt counter electrode and $\mathrm{Ag} / \mathrm{AgCl}$ ( $3 \mathrm{M}$ saturated solution of $\mathrm{NaCl}$ ) as a reference electrode. Thin films of the $\mathrm{Cs}_{3} \mathrm{Bi}_{2} \mathrm{I}_{9}: \mathrm{TiO}_{2}$ composites were prepared on top of fluoride-doped tin oxide (FTO) coated glasses (Sigma Aldrich, $\approx 8 \Omega / \mathrm{sq}$ ) by the doctor blade technique. A paste consisting of $200 \mathrm{mg}$ of the composite, $50 \mu \mathrm{l}$ of Triton X-100 (Sigma-Aldrich, laboratory-grade), $100 \mathrm{mg}$ of polyethylene glycol 10000 (Merck, for synthesis), $400 \mu$ of deionized water, and ethanol was used for the film preparation. A final calcination step at $400^{\circ} \mathrm{C}$ for two hours was applied in order to remove the organic materials. The as-prepared films were used as working electrodes for impedance measurements at $10 \mathrm{~Hz}$ in $0.1 \mathrm{~mol} / \mathrm{L} \mathrm{KNO}_{3}$ using a ZENNIUM Electrochemical Workstation (Zahner-Elektrik GmbH \& Co. KG). A solar simulator equipped with a xenon lamp $(300 \mathrm{~W}, 678 \mathrm{~W} \cdot \mathrm{m}-2)$ and an AM-1.5 G filter was employed for the photo-electrochemical measurements.

\subsection{Set-up for photocatalytic evaluation in aqueous phase}

In this study, methanol $\left(\mathrm{CH}_{3} \mathrm{OH}\right)$ was used as a model of organic pollutant in order to quantify the photocatalytic potential of the $\mathrm{Cs}_{3} \mathrm{Bi}_{2} \mathrm{I}_{9}: \mathrm{TiO}_{2}$ composite materials [55]. A closed quartz 
photoreactor was filled with $75 \mathrm{~mL}$ of a $100 \mathrm{mM}$ methanol aqueous solution. Single wavelength LED irradiation was used with two different light sources M455L3 (blue LED $455 \mathrm{~nm}$ ), and M365L2 (UV LED $365 \mathrm{~nm}$ ) purchased from Thorlab and equipped with a collimating lens. The emission spectra of the light sources are shown in the Supporting Information (Figure S1). The irradiation of the composite suspensions $(1 \mathrm{~g} / \mathrm{L})$ started after 30 minutes in the dark to ensure that the adsorption-desorption equilibrium was established. Liquid samples were withdrawn at regular time intervals. The catalyst was removed from the liquid phase by filtration through an RC membrane with a $0.2-\mu \mathrm{m}$ pore size (Phenomenex). The amount of photogenerated formaldehyde was determined after the oxidation of methanol by taking $300 \mu \mathrm{L}$ after specific illumination intervals. After addition of $600 \mu \mathrm{L}$ of the Nash reagent (0.02 M acetylacetone, $0.05 \mathrm{M}$ acetic acid, and $2 \mathrm{M}$ ammonium acetate), the yellow-colored diacetyldihydrolutidine (DDL) is formed and detected by fluorescence spectroscopy [55,56]. At an excitation wavelength of $405 \mathrm{~nm}$, the characteristic emission of DDL appears at $510 \mathrm{~nm}$. The fluorescence of DDL was measured in a well plate (Nunclon Delta Surface, Thermo Fisher Scientific Inc., USA) sample holder. The analysis was performed employing an F-7000 Fluorescence Spectrophotometer Hitachi equipped with a Xenon Lamp (FL parameter: 700 V PMT voltage, $5 \mathrm{~nm}$ excitation and emission slits, 2400 $\mathrm{nm} \mathrm{min}{ }^{-1}$ scan speed, $315 \mathrm{~nm}$ excitation wavelength, luminosity spectrum of 410-650 $\mathrm{nm}$ emission wavelength recorded).

Moreover, the reaction rate of the different photocatalysts was determined by considering a firstorder kinetic model according to the following equation Eq. 1:

$$
k=-\frac{d[A]}{[A]} \quad(\mathbf{1})
$$

where $[\mathrm{A}]$ is the concentration of the model pollutant and $k$ is the reaction rate.

The detection of hydroxyl radicals was performed by the use of terephthalic acid, which reacts 
with photogenerated hydroxyl radicals, yielding the fluorescent 2-hydroxyterephthalic acid (2HTA) [57]. Aqueous terephthalic acid solution $(0.5 \mathrm{mM})$ was mixed with $1 \mathrm{~g} / \mathrm{L}$ of catalyst, and the $\mathrm{pH}$ was adjusted to basic using $\mathrm{NaOH}$ solution $(2 \mathrm{mM})$. The solution was stirred for 30 minutes and then irradiated with a LED lamp. Sample from the solution were collected at different time intervals and filtrated to separate the catalyst. Finally, the fluorescence of the filtrate was measured by exciting at $315 \mathrm{~nm}$.

\section{RESULTS AND DISCUSSION}

\subsection{Catalyst characterization}

The XRD patterns of UV100 and the as-synthesized composites are shown in Figure 2. The UV100 diffraction pattern was compared with the JCDS-ICSD standards, and it was indexed to the tetragonal $\mathrm{TiO}_{2}$ anatase phase (JCPDS Card no. 21-1272). The peaks observed at $2 \theta$ values of $25.4^{\circ}, 38.5^{\circ}, 48.2^{\circ}, 54.4^{\circ}, 55.4^{\circ}$, and $62.7^{\circ}$ correspond to the (101), (004), (200), (105), (211), and (204) crystal planes [58]. Additional XRD patterns of the starting materials $\left(\mathrm{BiI}_{3}\right.$ and $\left.\mathrm{CsI}_{2}\right)$ and the $\mathrm{Cs}_{3} \mathrm{Bi}_{2} \mathrm{I}_{9}$ perovskite are shown in the Supporting Information. The XRD pattern of $\mathrm{Cs}_{3} \mathrm{Bi}_{2} \mathrm{I}_{9}$ exhibits a hexagonal crystallographic phase with space group P63/mmc $[53,59,60]$. In the XRD pattern of $\mathrm{Cs}_{3} \mathrm{Bi}_{2} \mathrm{I}_{9}$, closely spaced peaks convolute into a single broad peak, sometimes with an asymmetric shape. These complexities, together with the usual uncertainties arising from inhomogeneity in the size and shape of nanocrystals, made the determination of the crystallite size of $\mathrm{Cs}_{3} \mathrm{Bi}_{2} \mathrm{I}_{9}$ challenging. The XRD patterns obtained for the heterostructures after calcination show peaks of the pristine anatase- $\mathrm{TiO}_{2}$ (UV100) crystal phase without any changes. This result confirms that the perovskite nanoparticles, which are present in only low quantity $(<0.5 \mathrm{wt} \%)$, are dispersed on the $\mathrm{TiO}_{2}$ surface. No shift was measured in the peaks of the calcined samples confirming high thermal stability of the crystal structure. The presence of $\mathrm{Cs}_{3} \mathrm{Bi}_{2} \mathrm{I}_{9}$ was detected 
on the UV100-0.5 sample at $2 \theta$ equal to $29.6^{\circ}, 31.5^{\circ}, 38.7^{\circ}$, and $44.9^{\circ}$. In the as-synthesized heterostructures is diffraction peak was probability hidden by the high intensity of the $\mathrm{TiO}_{2}$ diffraction peak at $2 \theta=25.4^{\circ}$.

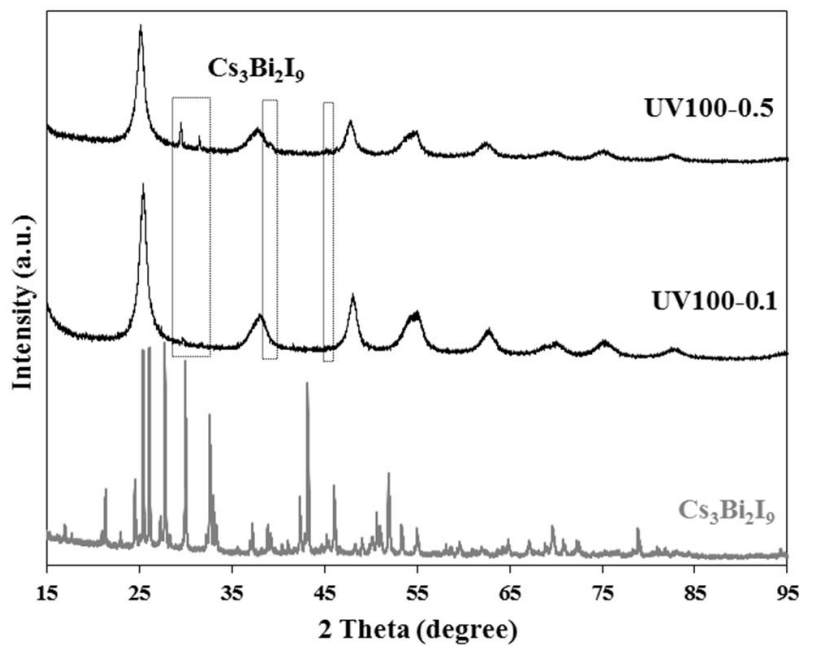

Figure 2: XRD patterns for precursors and synthesized materials

The optical bandgap of the materials was determined using UV-vis diffuse reflectance spectroscopy. The optical properties of the UV100-0.1 and UV100-0.5 composites were characterized by UV-vis spectroscopy at room temperature and compared with commercial UV100, used as a reference (Figure S3). The results exhibit that both the UV100-0.1 and UV1000.5 composites show a redshift of the absorption. The absorption edge of the bare UV100 was found to be $400 \mathrm{~nm}$, for UV100-0.1 and UV100-0.5 composites were about 580 and $630 \mathrm{~nm}$, respectively. This optical absorption may be responsible for driving the degradation reaction more efficiently under visible light illumination [61]. Unlike traditional semiconductors, $\mathrm{Cs}_{3} \mathrm{Bi}_{2} \mathrm{I}_{9}$ exhibits strong excitonic behavior even at room temperature. The excitonic absorption peak at 2.56 $\mathrm{eV}(485 \mathrm{~nm})$ is shown in Figure $\mathbf{S 3}$. The peak is usually related to the strong quantum confinement effect due to the $0 \mathrm{D}$ nature of $\left[\mathrm{Bi}_{2} \mathrm{I}_{9}\right]^{3-}$ bioctahedra [40]. The calculated bandgap from the Tauc 
plot of the absorbance data of $\mathrm{Cs}_{3} \mathrm{Bi}_{2} \mathrm{I}_{9}$ is reported in Supporting Information.

BET adsorption analysis was performed to detect the specific surface area of the employed materials. In general, Hombikat UV100 particles are mainly formed by small homogenous subparticles highly agglomerated, and the surface of the particles is full of pores producing a high specific surface area [62]. On the contrary, the perovskite has a very small surface area around 5 $\mathrm{m}^{2} / \mathrm{g}$ which is more than 50 times lower than $\mathrm{TiO}_{2}$. In the UV100-0.5 sample, containing $0.5 \mathrm{wt} \%$ $\mathrm{Cs}_{3} \mathrm{Bi}_{2} \mathrm{I}_{9}$, the surface area decreased to $74.4 \mathrm{~m}^{2} / \mathrm{g}$. However, while reducing the content of perovskite to $0.1 \mathrm{wt} \%$, the surface area slightly increased to $82.6 \mathrm{~m}^{2} / \mathrm{g}$, nearly three times less than the commercial UV100 $\left(284.98 \mathrm{~m}^{2} / \mathrm{g}\right)$. The formation of perovskite nanoclusters on the surface of the composites might result in a decrease in specific BET surface area of titanium by creating an excessive agglomeration on the surface of the UV100. Consequently, all the perovskite-based heterostructures presented a significantly smaller surface area respect the pristine $\mathrm{TiO}_{2}$. In order to observe the morphology of the as-synthesized powders, the SEM was used. Figure $\mathbf{3 A}-\mathbf{C}$ report the SEM images and the EDX analysis of the as-synthesized inorganic perovskite $\mathrm{Cs}_{2} \mathrm{Bi}_{3} \mathrm{I}_{9}$. The morphology was likely to be induced by a slow crystal growth rate since the synthesis was performed at low temperature $\left(60^{\circ} \mathrm{C}\right)$ and the DMF was slowly evaporated. The image clearly shows hexagonal structures in agreement with the XRD pattern (Figure S1).

The characteristic SEM images of the as-prepared microcrystals show particles of various size ranging from 10 to $15 \mu \mathrm{m}$ (Figure 3A). While the smaller particles exhibit irregular crystal shapes, the larger are hexagonal (Figure 3B). Energy-dispersive X-ray spectroscopy (EDX) measurements were performed to verify the percentage of elements in the sample, all showing prominent peaks (Figure 3C) [63]. Figure 3D-F show SEM images and EDX analysis for the UV100-0.5 composite with $\mathrm{Cs}_{3} \mathrm{Bi}_{2} \mathrm{I}_{9}$ content of $0.5 \%$. In general, Hombikat UV100 nanoparticles clusters 
exhibit a narrow range of homogeneous particles in shape and size. The surface of the particles, usually full of pores, may produce high specific surface area herein in agreement with the observations made with BET measurements [64]. Moreover, this marked porosity may facilitate the implant of functional species [62]. The presence of $\mathrm{Cs}_{3} \mathrm{Bi}_{2} \mathrm{I}_{9}$ in a composite emerge many insular aggregates and the surfaces of $\mathrm{TiO}_{2}$ become rough as revealed in Figure 3DFigure 3: $A$ and B) SEM images for bare perovskite Cs3Bi219, C) EDX analysis for bare perovskite Cs3Bi2I9, D) SEM images for composite UV100-0.1 E) EDX analysis for composite. In order to obtain an understanding of the interfacial interaction between UV100 and halide perovskite, the heterostructure was characterized by TEM. TEM images confirmed that the composites exhibit similar morphology of pristine material, indicating the structure of the singular materials remains unchanged after the solvent treatment. The TEM picture in Figure 3E shows different lattice fringes of the as-synthesized halide perovskite on the UV100, revealing the formation of heterostructure after the as performed synthesis. Figure 3F displayed the EDX analysis of the as synthesized composite. These data confirm the coexistence of $\mathrm{TiO}_{2}$ and $\mathrm{Cs}_{3} \mathrm{Bi}_{2} \mathrm{I}_{9}$ without exhibiting any remarkable contamination by other chemical species.
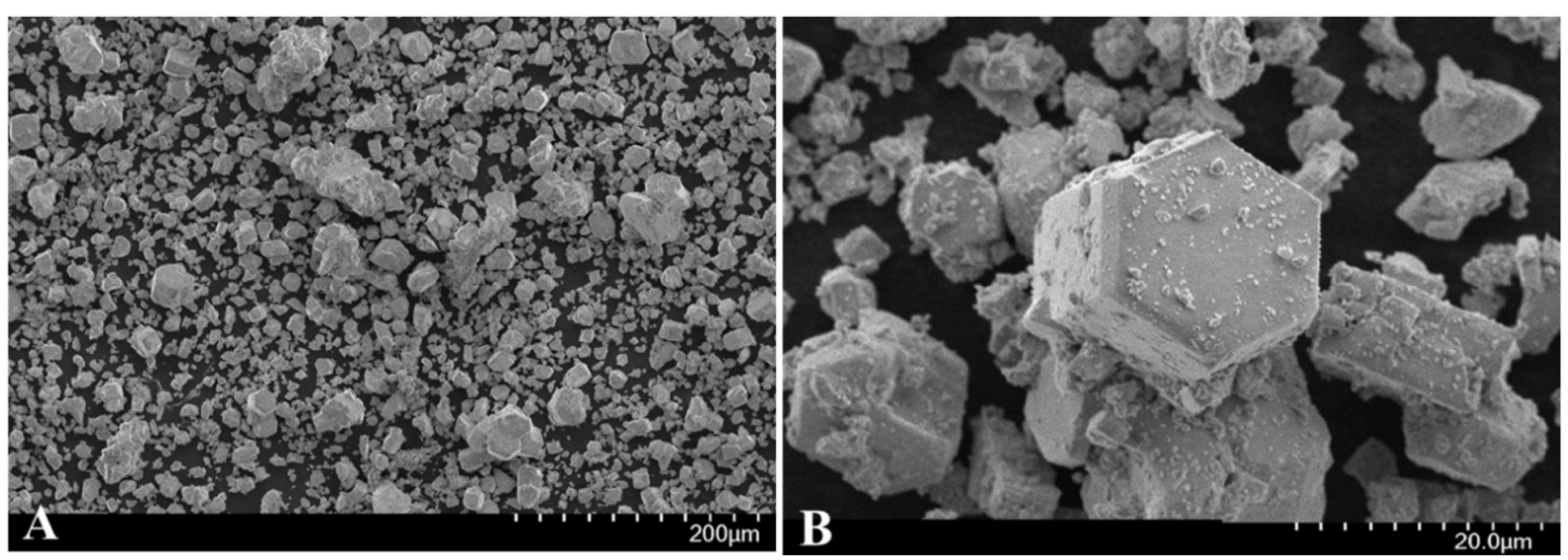

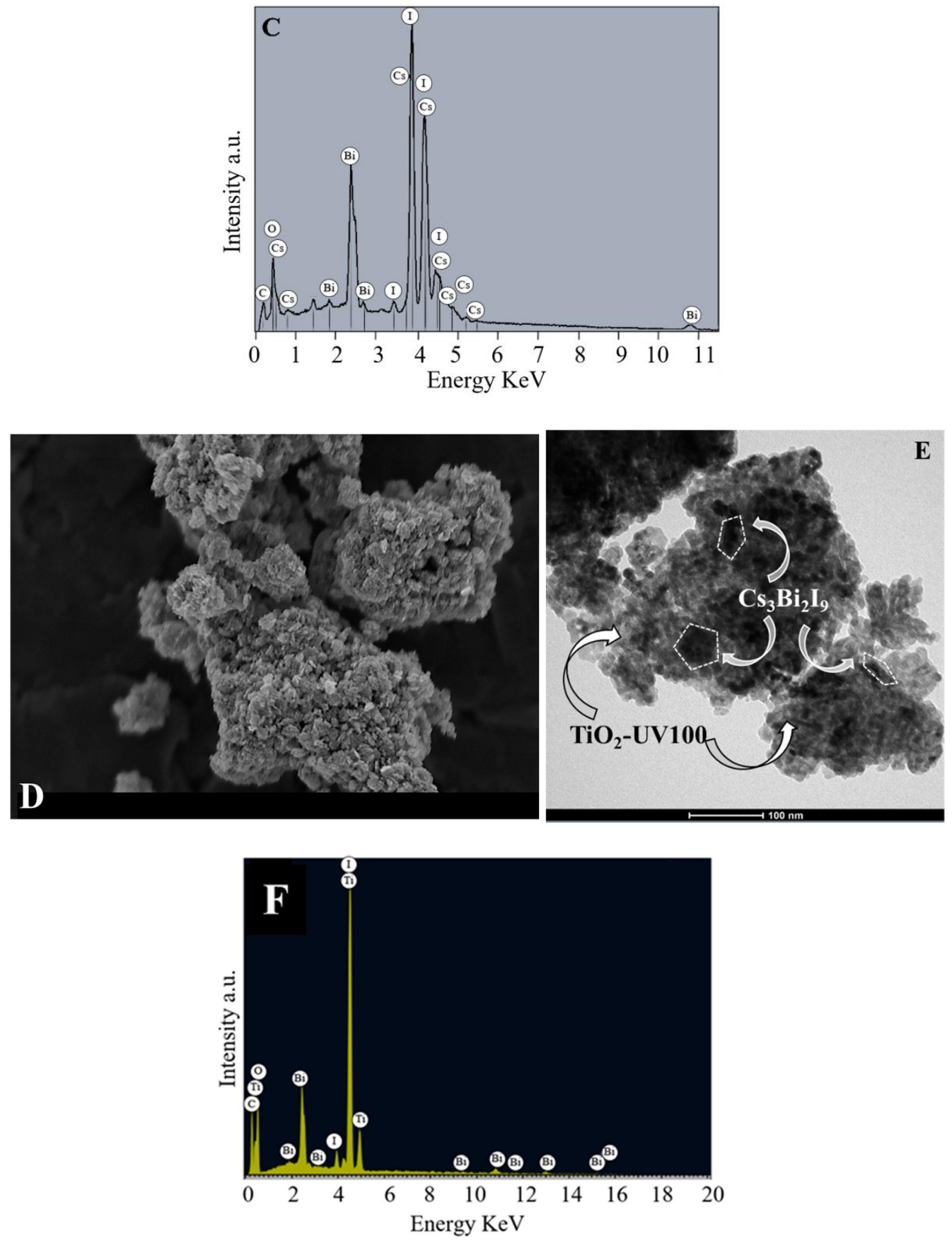

Figure 3: A and B) SEM images for bare perovskite $\left.C s_{3} B i_{2} I_{9}, C\right)$ EDX analysis for bare perovskite $\left.C_{3} B i_{2} I_{9}, D\right) S E M$ images for composite UV100-0.1 E) EDX analysis for composite UV100-0.1

X-ray photoelectron spectroscopy (XPS) was performed to confirm the elemental composition and the valence of the single elements on the surface of the samples. The specific survey spectrum of 
the halide perovskite is discussed in the Supporting Information (Figure S5). According to the survey spectrum of the as-synthesized composite, the detected elements include Ti, Bi, I, Cs, and $\mathrm{O}$ (Figure 6). The silver peak can be ascribed to the elemental composition of the holder of the instrument. The carbon peak at $284.9 \mathrm{eV}$ is attributable to the atmospheric carbon, introduced during the sample preparation and measurement. The XPS proves the successful preparation of composition between $\mathrm{TiO}_{2}$ and $\mathrm{Cs}_{3} \mathrm{Bi}_{2} \mathrm{I}_{9}$. The obtained binding energy peaks confirm the presence of dominant elements: Ti and O. Figure 4B show a high-resolution XPS spectrum of the Ti 2p region. The core level of the binding energy of Ti $2 \mathrm{p}_{3 / 2}$ and $\mathrm{Ti} 2 \mathrm{p}_{1 / 2}$ was found at $458.8 \mathrm{eV}$ and $464.8 \mathrm{eV}$, respectively. It must be noted that the peaks of $\mathrm{Ti} 2 \mathrm{p}_{1 / 2}$ and $\mathrm{Bi} 4 \mathrm{~d}_{3 / 2}$ may partially overlapped. The XPS peak at $465.4 \mathrm{eV}$ can also be assigned to $\mathrm{Bi} 4 \mathrm{~d}_{3 / 2}$. The peak located at 530.4 $\mathrm{eV}$ is shown in Figure 4B, indicates the presence of the main component corresponding to metal oxide bond Ti-O. It may also be considered the presence of adsorbed $\mathrm{OH}^{-}$and $\mathrm{CO}_{3}{ }^{2-}$ ions which correspond to $532 \mathrm{eV}$ signal [65]. Since the intensity of the carbon peak indicated a very small amount of $\mathrm{C}$, the component in the $\mathrm{O} 1 s$ spectra were mainly assigned to $\mathrm{OH}^{-}$. As expected, the peaks belonging to the perovskite elements were found to be very weak and noisy because of the low content in the composite. However, the presence of bismuth, cesium, and iodine was confirmed as depicted in Figure 4B. The peak of Bi located around $160 \mathrm{eV}$ indicates that Bi species exists in the $3^{+}$oxidation state. Furthermore, the high-resolution XPS spectra of Cs reveals the binding energy curves of $\mathrm{Cs} 3 \mathrm{~d}_{3 / 2}$ and $\mathrm{Cs} 3 \mathrm{~d}_{5 / 2}$ at 738.7 and $724.8 \mathrm{eV}$, respectively. 

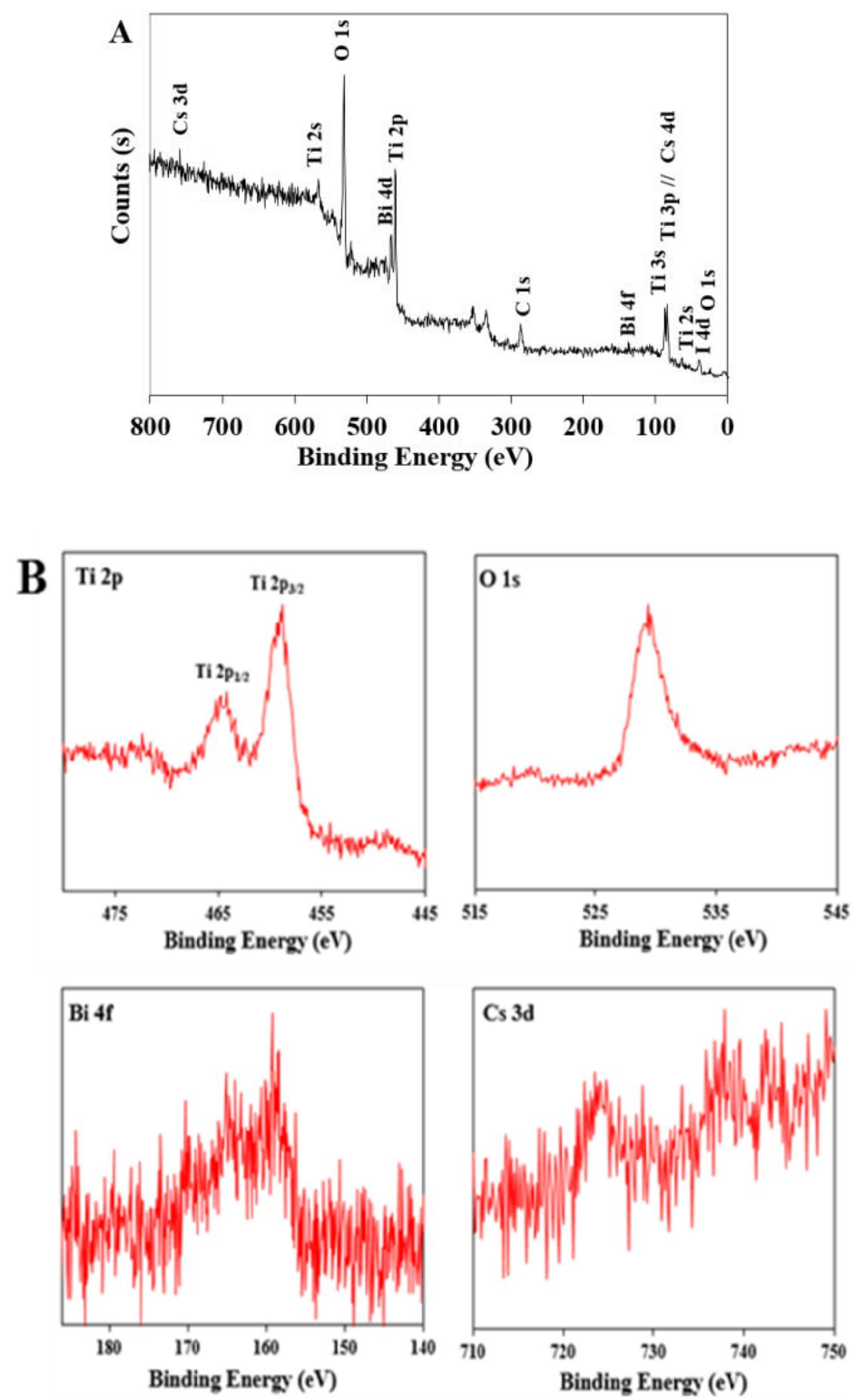

Figure 4: A) XPS survey spectrum of the UV100-0.1 heterostructure B) T2p, O 1s, Bi 4f, and Cs $3 d$ spectra, respectively.

The photocatalytic activity is not only related to the light absorption capacity of the photocatalyst, but also to its ability to separate the photogenerated charge carriers and to catalyze the reduction and oxidation reactions [66]. Thus, it is important not only to evaluate the structural and optical properties but also the electronic properties of a semiconductor in order to understand the observed 
photocatalytic performance. The position of Fermi level and flat band potential $\left(\mathrm{V}_{\mathrm{fb}}\right)$ in the illuminated semiconductor electrode, relative to the redox potential of electrolyte, is interesting information that plays a key role in the application of semiconductor. For an n-doped semiconductor, $\mathrm{V}_{\mathrm{fb}}$ lies close to the conduction band edge. Thus, the band edge energetic position of the conduction band can be estimated from the $V_{f b}$ value [67]. Capacitance-voltage measurements of films in electrolyte solutions are frequently used to construct Mott-Schottky plots, from which $\mathrm{V}_{\mathrm{fb}}$ of the semiconductor can be extracted. This method provides a direct measurement of the energetic interfacial alignment [68]. Herein, the Mott-Schottky results were conducted to confirm the relationship between the energetic levels at the semiconductor-electrolyte interface and the observed photocatalytic activity of the $\mathrm{Cs}_{3} \mathrm{Bi}_{2} \mathrm{I}_{9}: \mathrm{TiO}_{2}$ heterostructures in aqueous oxidation processes. Figure $\mathbf{5}$ shows the results obtained for the capacitance-voltage measurements. The analysis was performed employing $\mathrm{Cs}_{3} \mathrm{Bi}_{2} \mathrm{I}_{9}: \mathrm{TiO}_{2}$ film deposited on top of FTO glass, $\mathrm{KNO}_{3}$ was used as an electrolyte. In general, the extrapolation of the linear fit of the straight portion of the curve to $1 /(\mathrm{C} / \mathrm{A})^{2}=0$ gives an approximated value of the conduction band position $\approx V_{\mathrm{fb}}$. The energetic position of the valence band $\left(\mathrm{E}_{\mathrm{vb}}\right)$ can be calculated when the value of the bandgap energy $\left(\mathrm{E}_{\mathrm{g}}\right)$ is known:

$$
E_{v b}=E_{c b}+E_{g}
$$

There are many factors that may affect the $\mathrm{V}_{\mathrm{fb}}$ measurements, including defects induced during the synthetic process. For example, it is well known that for anatase $\mathrm{TiO}_{2}$ a frequency dependence in the Mott-Schottky plots may be caused by the inhomogeneity of the donor density near the surface [69]. Such effects might also influence the measurements performed for the $\mathrm{Cs}_{3} \mathrm{Bi}_{2} \mathrm{I}_{9}: \mathrm{TiO}_{2}$ heterostructures. Thus, the obtained $\mathrm{V}_{\mathrm{fb}}$ results were considered in a qualitatively rather than quantitativel manner. The positive slope of the straight line indicates that the as-synthesized 
material was an n-type semiconductor. However, in the case of the as-synthesized heterostructures, it is interesting to note both the results confirm the feature characteristic of an n-junction, wherewith three flat band potential values $-0.37 \mathrm{~V}$ for UV100 [70,71], $-0.75 \mathrm{~V}$ for the UV100-0.1 heterostructure. The Mott-Schottky plots for the bare perovskite are presented in Supporting Information. The energetic position of the $\mathrm{V}_{\mathrm{fb}}$ can be considered similar to the position of the conduction band; it can be assumed that the electrons of the conduction band of the heterostructure have higher reductive power respect to the bare UV100. Thus, the reduction of $\mathrm{O}_{2}$ to $\mathrm{O}_{2} \bullet$ and $\mathrm{H}^{+}$ to $\mathrm{H}_{2}$ by photogenerated electrons was found to be thermodynamically more favored for the heterostructure than for the bare UV100, resulting in a higher photocatalytic activity. Another possible explanation of the results is the transfer of the excited electrons from one material to the other, resulting in a decrease of recombination rate.

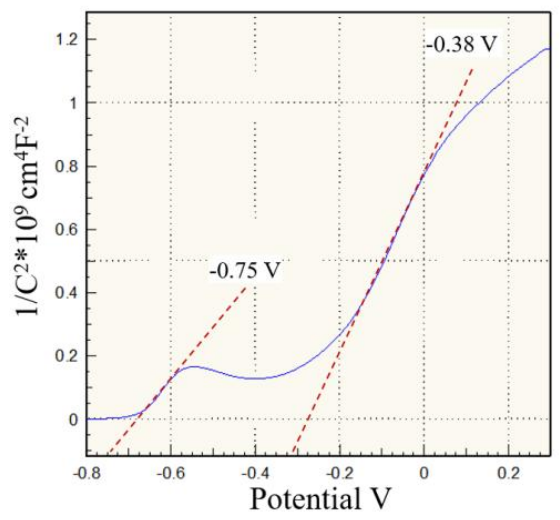

Figure 5: Mott-Schottky plot for UV100-0.1 composite films on FTO

Moreover, the heterojunction formation should be considered a key factor to enhance the activity of the material. In semiconductor heterojunctions, the transfer direction of the photogenerated charge carriers depends on the position of the energetic levels (CB and VB). In general, when $\mathrm{TiO}_{2}$ is coupled with another semiconductor, spatial charge separation may occur [72]. In the $\mathrm{Cs}_{3} \mathrm{Bi}_{2} \mathrm{I}_{9}: \mathrm{TiO}_{2}$ heterostructure, the energetic position of $\mathrm{TiO}_{2}$ and $\mathrm{Cs}_{3} \mathrm{Bi}_{2} \mathrm{I}_{9}$ are shown in Figure 6. 
Due to this energy band alignment, photogenerated electrons are transferred from the $\mathrm{CB}$ of $\mathrm{Cs}_{3} \mathrm{Bi}_{2} \mathrm{I}_{9}$ into the $\mathrm{CB}$ of $\mathrm{TiO}_{2}$, while photogenerated holes can be transferred from the $\mathrm{VB}$ of $\mathrm{TiO}_{2}$ into the $\mathrm{CB}$ of $\mathrm{Cs}_{3} \mathrm{Bi}_{2} \mathrm{I}_{9}$. This allows a more efficient charge separation in the $\mathrm{Cs}_{3} \mathrm{Bi}_{2} \mathrm{I}_{9}: \mathrm{TiO}_{2}$ heterojunction than in $\mathrm{TiO}_{2}$ or $\mathrm{Cs}_{3} \mathrm{Bi}_{2} \mathrm{I}_{9}$ alone.

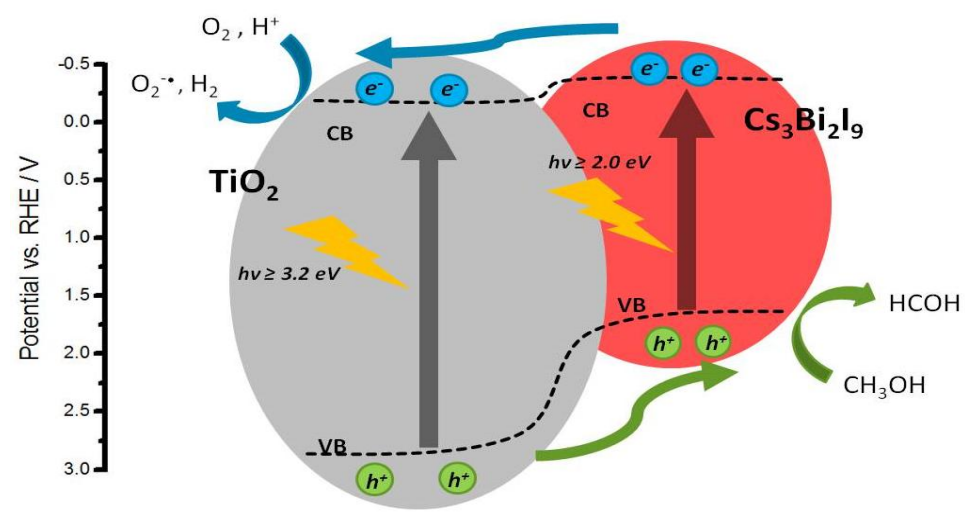

Figure 6: Band alignment in the UV100:Cs $\mathrm{Bi}_{2} \mathrm{I}_{9}$ heterostructures

$\mathrm{TiO}_{2}$ and $\mathrm{Cs}_{3} \mathrm{Bi}_{2} \mathrm{I}_{9}$ form a type II heterojunction allowing a more efficient charge separation than $\mathrm{TiO}_{2}$ or $\mathrm{Cs}_{3} \mathrm{Bi}_{2} \mathrm{I}_{9}$ alone. Photogenerated electrons were transferred into the $\mathrm{CB}$ of $\mathrm{TiO}_{2}$ while photogenerated holes were transferred into the $\mathrm{VB}$ of $\mathrm{Cs}_{3} \mathrm{Bi}_{2} \mathrm{I}_{9}$. In aerobic reaction condition the CB electrons might react with $\mathrm{O}_{2}$ to yield $\mathrm{O}_{2}^{-\bullet}$ or in anaerobic reaction condition $\mathrm{H}^{+}$to $\mathrm{H}_{2}$, while VB holes might oxidize methanol into formaldehyde.

Photocurrent measurements under solar simulator, with and without methanol, were conducted in order to evaluate the relevant properties and illustrate the enhanced electron transfer in the composites. Figure 7 shows the current density as a function of time by switching on and off the light at $20 \mathrm{~s}$ intervals. In the absence of methanol, the current density was found to be extremely small. On the contrary, the current density increased when methanol was added to the electrolyte. In particular, the current density rose subsequently when the light was on and then gradually increased to a steady state. Afterward, the current density decreased instantly as the light was 
turned off. The current density on the composite deposited on FTO was clearly higher during illumination.

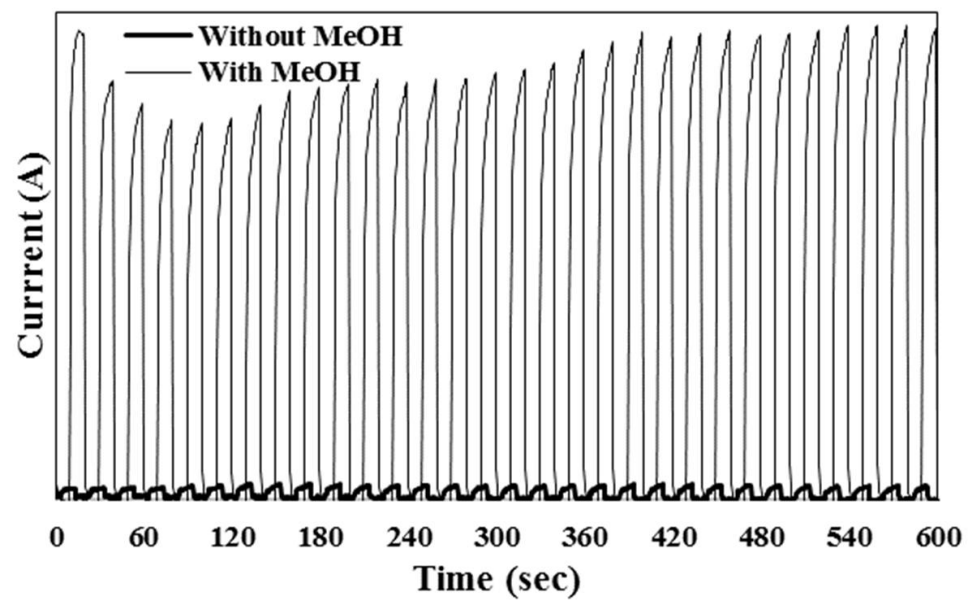

Figure 7: Time-resolved current measurement, UV100-0.1 composite on FTO, in a presence and absence of MeOH

\subsection{Performance of Photocatalysis}

\subsubsection{MeOH oxidation into formaldehyde}

The photocatalytic reforming of methanol into formaldehyde lately leads to oxidizing to formic acid and finally to $\mathrm{CO}_{2}$ and water [73]. When the semiconductor absorbs a photon with an energy equal to or higher than its bandgap, the electrons migrate from the valence band (VB) into the conduction band (CB). This results in the formation of holes $\left(\mathrm{h}^{+}{ }_{\mathrm{vb}}\right)$ and electrons $\left(\mathrm{e}^{-} \mathrm{cb}\right)$ in the VB and $\mathrm{CB}$, respectively. The photogenerated holes, when do not recombine with $\mathrm{e}^{-}$cb, react with surface hydroxyl groups $\left({ }^{-} \mathrm{OH}\right)$ or adsorbed water molecules to produce hydroxyl $(\bullet \mathrm{OH})$ radicals. Hydroxyl radicals are strong and non-selective oxidizing agents in photocatalytic reactions. [11] The radicals rapidly react with surface absorbed methanol that is oxidized primarily into formaldehyde and then into other species. In addition, the photogenerated $\mathrm{e}_{\mathrm{cb}}^{-}$can react with electron acceptors, such as $\mathrm{O}_{2}$, dissolved in the solution or adsorbed on the surface of the

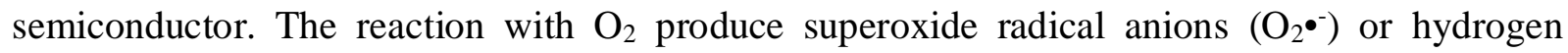


peroxide $\left(\mathrm{H}_{2} \mathrm{O}_{2}\right)$, that may be utilized for the oxidation of methanol through the intermediate formation of $\bullet \mathrm{OH}$ radicals [10]. The photocatalytic oxidation of methanol into formaldehyde was expressed in terms of the increase of the intensity of the peaks corresponding to DDL, as a function of time of irradiation. It has been reported by Nash [56] that two moles of acetylacetone react with one mole of formaldehyde to give one mole of DDL. The characteristic emission peak of DDL, corresponding at the formation of formaldehyde, was found to be at $510 \mathrm{~nm}$. The peaks corresponding to DDL increase in intensity as a function of time of irradiation indicating the conversion of methanol to formaldehyde, which was be quantified by calibration.

Previously, two control experiments were performed. Initially, the effect of light was tested on methanol as a model contaminant. Direct photolysis of methanol upon UV and visible light was found to be negligible. Similar results were reported in other studies before [55,73]. A second control experiment was conducted in dark conditions and in the presence of the composite catalyst (UV100-0.1). Any degradation was recorded. In general, 30 minutes of dark absorption was performed before switch on the light in order to reach adsorption-desorption equilibrium. The results highlight three main points. First, the enhancement of peak at $510 \mathrm{~nm}$ in both Figure 8A and $\mathbf{B}$ means that formaldehyde appeared as an oxidation product of methanol. Moreover, the peaks appeared to increase along time of irradiation. Therefore, the results confirm the oxidation of methanol into formaldehyde during the photocatalytic experiments. Finally, Figure 8A-B are evident that photocatalysis under UV irradiation shows remarkable higher efficiency respect to the visible light irradiation. 

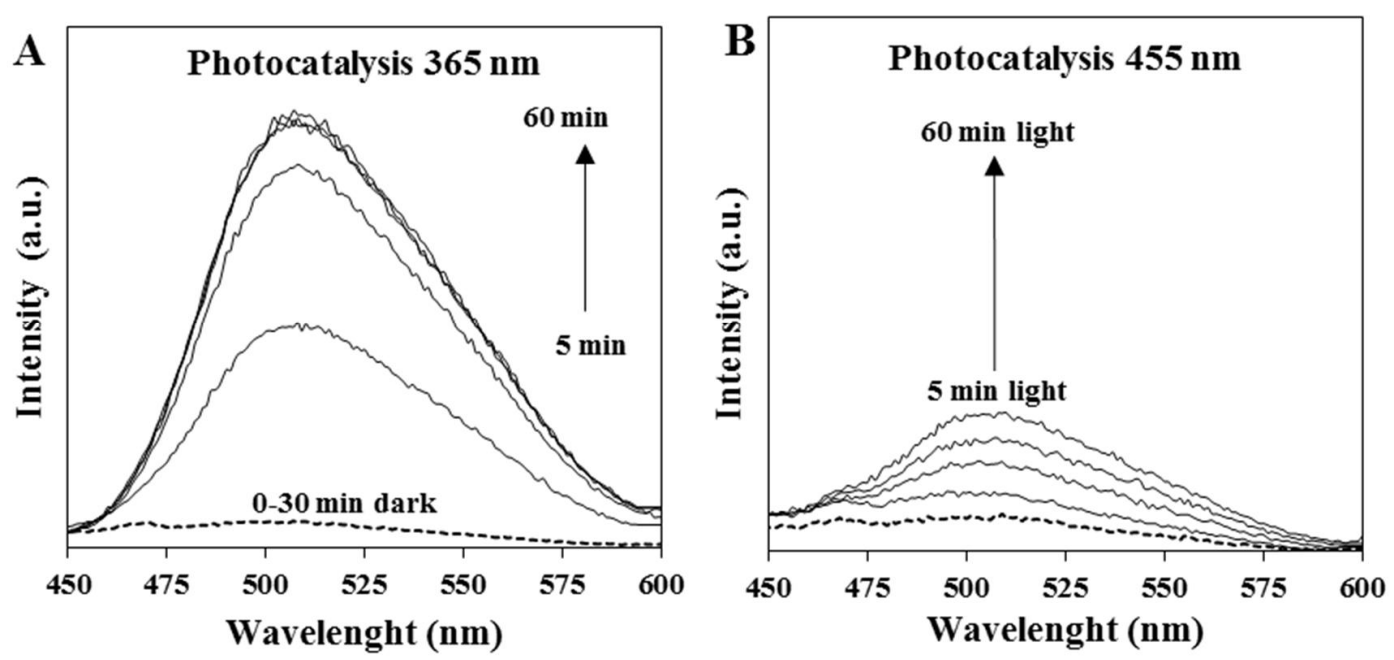

Figure 8: A) Photocatalytic evolution in PL spectra of methanol oxidation as a function of irradiation time under 365nm-light irradiation over UV100-0.1, B) Photocatalytic evolution in PL spectra as a function of irradiation time under 455nm-light irradiation over UV100-0.1.

The reforming of methanol to formaldehyde was performed in water solution under UV and visible-light irradiation. Figure 9A and $\mathbf{B}$ show the variation in formaldehyde concentration during light irradiation for the different photocatalysts under UV and visible-light irradiation, respectively. Under UV light irradiation (Figure 9A), the observed photocatalytic activity can be primarily attributed to the transition of electrons from the valence band to the conduction band of $\mathrm{TiO}_{2}$ due to the absorption of UV radiation having energy higher than the bandgap energy. The photocatalytic activities of the heterostructures UV100-0.1 and UV100-0.5 were found to be relatively higher when compared with the activity reported for commercial UV100. It must be noticed that after 15 minutes the concentration of formaldehyde starts to be constant, this may be associated to complete conversion of methanol. Moreover, the UV100-0.1 composite showed the best photocatalytic activity under visible light irradiation respect all the other synthesized composites, as shown in Figure 9B. In particular, when the load of perovskite introduced in the 
composite was enhanced, the photodegradation was reduced. The decrease may be associated with the possibility of a different degree of aggregation according to the amount of the perovskite present in the composite. Finally, this effect may also be related to the fact that perovskite may occupy the adsorption site on $\mathrm{TiO}_{2}$ surface by decreasing the adsorption rate of the reactant. Moreover, the efficiencies in methanol degradation process of the as-synthesized composites were compared using the calculated rate of reaction, as shown in Eq. 1. The results are listed in Table 2. The results show that the UV100-0.1 and UV100-0.5 heterostructures exhibited improved photocatalytic activity both under visible and UV-light irradiation. In this evaluation, the reaction rate was applied in the first 10 minutes of experiments where the reaction shows a linear behavior. The degradation appeared to be considerably faster under UV light irradiation in comparison with the visible-light irradiation. The UV100-0.5 and UV100-0.1 composites showed a reaction rate of $50 \%$ and $44 \%$ higher in comparison with the bare UV100, respectively. Moreover, the methanol was almost completely converted within 15 minutes, under UV-light irradiation with UV100-0.5 and UV100-0.1 composites. On the contrary, UV100 nanoparticles irradiated under UV-light showed the complete removal of methanol after 120 minutes. Since the photon energy is lower than the bandgap energy of UV100 nanoparticles under $455 \mathrm{~nm}$, visible light illumination and the transfer of electrons from the valence band to the conduction band was not expected to occur. In this case, the perovskite acts as a photosynthesizer, and it can harvest the visible light. Charge carriers can be photogenerated on perovskite surface under visible-light illumination as shown in DRS light-absorption measurement. In this case, the photocatalytic activity of $\mathrm{TiO}_{2}$ can be extended to the visible light range when combined with the narrower bandgap.

Moreover, the photocatalytic performance was also expected to be improved within the heterojunction interface because of the two materials allowed the migration of the charge carriers, 
which hinter also their fast recombination. Under visible light irradiation, remarkably superior efficiency was achieved by the UV100-0.1 respect to all the other prepared composites.
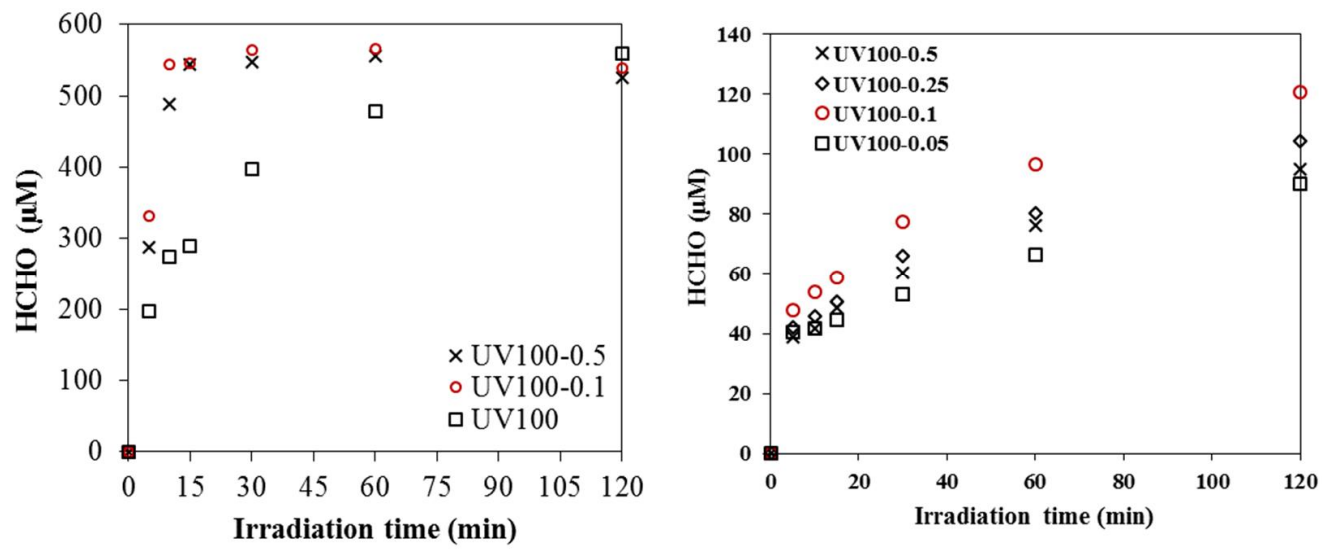

Figure 9: A) Photocatalytic oxidation of $\mathrm{MeOH}$ to the $\mathrm{HCHO}$ under $U V$-light irradiation, B) Photocatalytic oxidation of $\mathrm{MeOH}$ to the $\mathrm{HCHO}$ under visible-light irradiation

Table 2: Reaction rates of photocatalytic oxidation $\mathrm{MeOH}$ under UV and visible light irradiation

\begin{tabular}{c|ccc} 
& UV100-0.1 & UV100-0.5 & UV100 \\
\hline $\boldsymbol{k}\left(\boldsymbol{m i n}^{-1}\right)-\mathbf{3 6 5} \boldsymbol{n m}$ & 1.51 & 1.72 & 0.84 \\
$\boldsymbol{k}\left(\mathrm{min}^{-1}\right)-\mathbf{4 5 5} \mathrm{nm}$ & 0.99 & 0.99 & 0.95 \\
$\boldsymbol{R}^{2}$ & 0.05 & 0.03 & - \\
& 0.95 & 0.98 & -
\end{tabular}

In addition, the recyclability test of UV100-0.1 composite has been evaluated for three times without observing any significant loss in the efficiency (Figure 10). The results demonstrate that UV100-0.1 composite has great potential and good stability and may be considered as new photocatalytic material to use in water treatment. 

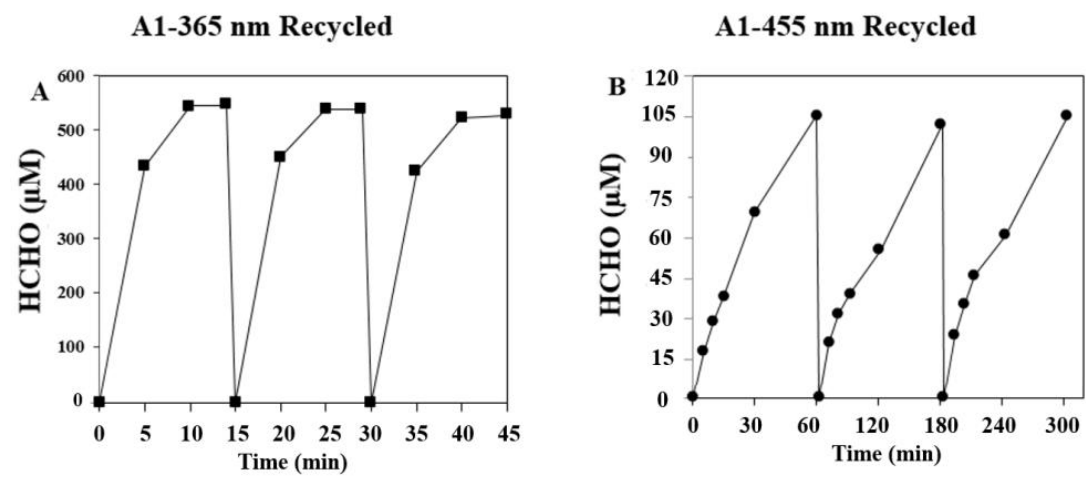

Figure 10: Recycling test for UV100-0.1 under UV and visible-light irradiation

In order to ensure the photocatalytic stability of the as prepared nanocomposite, the XRD patterns before and after reaction were recorded. Figure 11 displays the patterns for the as-prepared composite, before and after treatment; the pattern of pristine UV100 is also shown as a reference. As visible from the figure, the XRD peaks after photocatalytic reaction are similar to that before reaction. It indicates that the structure of the as-prepared material does not change during the photocatalytic process, and the stability of photocatalytic activity is depended on the stability of the structure.

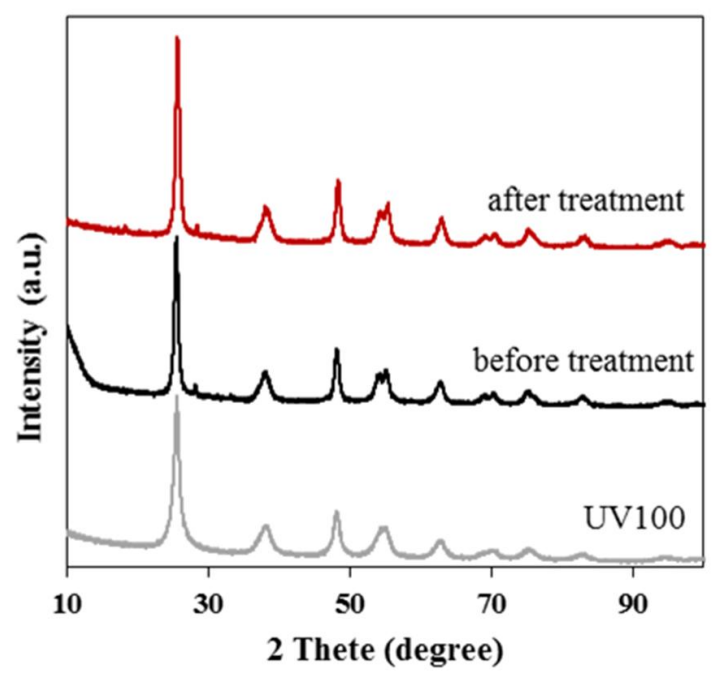

Figure 11: XRD patterns of the as synthesized composite before and after treatment and the bare UV100 as reference

\subsubsection{Formation of hTa: $\bullet$ OH evaluation}

As already mentioned, $\bullet \mathrm{OH}$ plays an important role in the organic pollutants abatements in wastewater treatments. In aqueous solutions, the direct measurement of $\bullet \mathrm{OH}$ is highly difficult due 
to its low concentration and short lifetime. Terephthalic acid (TA) has proven to be suitable for the $\bullet \mathrm{OH}$ quantification [74-76]. The fluorescence method analyses carried out to detect the 2hydroxyterephthalic acid (hTA) As an oxidation product of TA. TA was found to be more stable with respect to other probes used such as benzene, nitrobenzene [57]. The formation of hydroxyl radicals $\bullet \mathrm{OH}$ under irradiation was detected by the fluorescence-technique using terephthalic acid as a fluorescence probe molecule (Figure 12). The gradual increase in the PL intensity was observed at about $425 \mathrm{~nm}$, which indicates the formation of 2-hydroxyterephthalic acid produced by a chemical reaction between $\mathrm{TA}$ and $\bullet \mathrm{OH}$ formed during irradiation of the photocatalytic process.
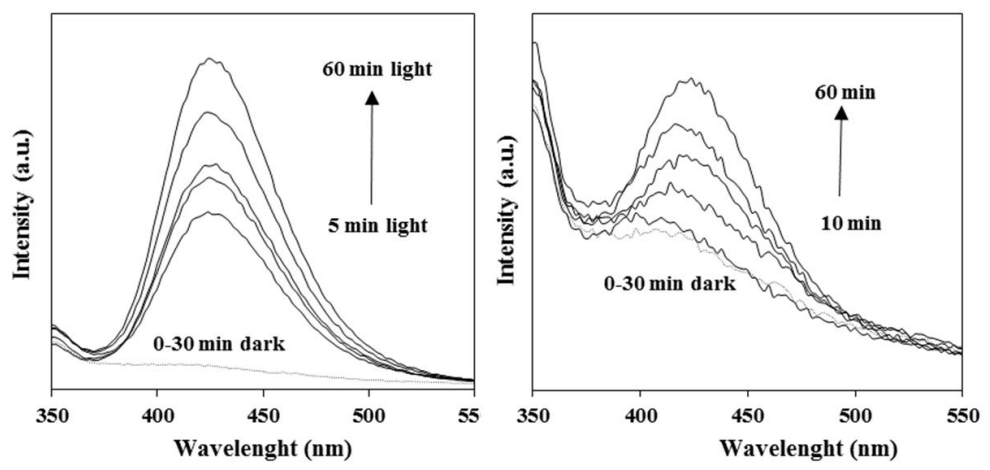

Figure 12: Fluorescence spectral changes with UV and visible-light irradiation time in a solution of terephthalic acid with UV100-0.1 under UV and visible light

\section{CONCLUSIONS}

In summary, the heterostructure $\mathrm{Cs}_{3} \mathrm{Bi}_{2} \mathrm{I}_{9}: \mathrm{TiO}_{2}$ composites were successfully synthesized via a simple wet-chemical method and applied for the photocatalytic decomposition of methanol. Under UV and visible-light illumination, the composites, especially UV100- 0.1 and UV100-0.5 were found to have a higher photocatalytic activity than pure Hombikat UV100 $\mathrm{TiO}_{2}$. According to the optical measurements and the electrochemical studies, the heterostructures benefit not only of an 
extended light-harvesting in the visible light region but also of increased charge separation. The increased photocatalytic activity under UV light irradiation may be ascribed to the simultaneous contribution of the perovskite and UV-100, acting as light-absorbing heterojunction. On the other hand, the activity under visible light irradiation can be mainly addressed to perovskite material which as like redox mediator.

\section{Acknowledgements}

Maa-javesitekniikantuki Foundation is gratefully acknowledged for the financial support. Moreover, we thank Luis I. Granone and the Laboratory of Nano and Quantum Engineering (LNQE) for providing electrochemical and XRD measurements. 


\section{REFERENCES}

[1] W. Zhang, S. Yang, J. Li, W. Gao, Y. Deng, W. Dong, C. Zhao, G. Lu, Visible-to-ultraviolet Upconvertion: Energy transfer, material matrix, and synthesis strategies, Appl. Catal. B Environ. 206 (2017) 89-103. doi:10.1016/j.apcatb.2017.01.023.

[2] P. Lianos, Review of recent trends in photoelectrocatalytic conversion of solar energy to electricity and hydrogen, Appl. Catal. B Environ. 210 (2017) 235-254. doi:10.1016/j.apcatb.2017.03.067.

[3] O. Lefebvre, R. Moletta, Treatment of organic pollution in industrial saline wastewater: A literature review, Water Res. 40 (2006) 3671-3682. doi:10.1016/j.watres.2006.08.027.

[4] D. Wang, S.C. Pillai, S.H. Ho, J. Zeng, Y. Li, D.D. Dionysiou, Plasmonic-based nanomaterials for en vironmental remediation, Appl. Catal. B Environ. 237 (2018) 721-741. doi:10.1016/j.apcatb.2018.05.094.

[5] C. Yang, H. Chen, G. Zeng, G. Yu, S. Luo, Biomass accumulation and control strategies in gas biofiltration, Biotechnol. Adv. 28 (2010) 531-540. doi:10.1016/j.biotechadv.2010.04.002.

[6] S. Suárez, M. Yates, A.L. Petre, J.A. Martín, P. Avila, J. Blanco, Development of a new $\mathrm{Rh} / \mathrm{TiO} 2$-sepiolite monolithic catalyst for N2O decomposition, Appl. Catal. B Environ. 64 (2006) 302-311. doi:10.1016/j.apcatb.2005.12.006.

[7] F. Teng, Z. Liu, A. Zhang, M. Li, Photocatalytic Performances of Ag3PO4Polypods for Degradation of Dye Pollutant under Natural Indoor Weak Light Irradiation, Environ. Sci. Technol. 49 (2015) 9489-9494. doi:10.1021/acs.est.5b00735.

[8] A.O.T. Patrocinio, J. Schneider, M.D. França, L.M. Santos, B.P. Caixeta, A.E.H. Machado, D.W. Bahnemann, Charge carrier dynamics and photocatalytic behavior of $\mathrm{TiO}<\mathrm{inf}>2</$ inf $>$ nanopowders submitted to hydrothermal or conventional heat treatment, RSC Adv. 5 (2015) 70536-70545. doi:10.1039/c5ra13291f.

[9] D. Spasiano, R. Marotta, S. Malato, P. Fernandez-Ibañez, I. Di Somma, Solar photocatalysis: Materials, reactors, some commercial, and pre-industrialized applications. A comprehensive approach, Appl. Catal. B Environ. 170-171 (2015) 90-123. doi:10.1016/j.apcatb.2014.12.050.

[10] T.S. Natarajan, H.C. Bajaj, R.J. Tayade, Enhanced direct sunlight photocatalytic oxidation of methanol using nanocrystalline $\mathrm{TiO} 2$ calcined at different temperature, J. Nanoparticle 
Res. 16 (2014) 2713. doi:10.1007/s11051-014-2713-7.

[11] J. Kou, C. Lu, J. Wang, Y. Chen, Z. Xu, R.S. Varma, Selectivity Enhancement in Heterogeneous Photocatalytic Transformations, Chem. Rev. 117 (2017) 1445-1514. doi:10.1021/acs.chemrev.6b00396.

[12] A. Kudo, Photocatalysis, Appl. Catal. B Environ. $46 \quad$ (2003) 703. doi:10.1016/j.apcatb.2003.08.002.

[13] C. Martínez, S. Vilariño, M.I. Fernández, J. Faria, M.L. Canle, J.A. Santaballa, Mechanism of degradation of ketoprofen by heterogeneous photocatalysis in aqueous solution, Appl. Catal. B Environ. 142-143 (2013) 633-646. doi:10.1016/j.apcatb.2013.05.018.

[14] S.A.A. Nakhli, K. Ahmadizadeh, M. Fereshtehnejad, M.H. Rostami, M. Safari, S.M. Borghei, Biological removal of phenol from saline wastewater using a moving bed biofilm reactor containing acclimated mixed consortia, Springerplus. 3 (2014) 1-10. doi:10.1186/2193-1801-3-112.

[15] J. Saien, H. Nejati, Enhanced photocatalytic degradation of pollutants in petroleum refinery wastewater under mild conditions, J. Hazard. Mater. 148 (2007) 491-495. doi:10.1016/j.jhazmat.2007.03.001.

[16] S. Loeb, R. Hofmann, J.H. Kim, Beyond the Pipeline: Assessing the Efficiency Limits of Advanced Technologies for Solar Water Disinfection, Environ. Sci. Technol. Lett. 3 (2016) 73-80. doi:10.1021/acs.estlett.6b00023.

[17] H. Sun, G. Li, X. Nie, H. Shi, P.K. Wong, H. Zhao, T. An, Systematic approach to in-depth understanding of photoelectrocatalytic bacterial inactivation mechanisms by tracking the decomposed building blocks, Environ. Sci. Technol. 48 (2014) 9412-9419. doi:10.1021/es502471h.

[18] S. Huang, Y. Xu, Q. Liu, T. Zhou, Y. Zhao, L. Jing, H. Xu, H. Li, Enhancing reactive oxygen species generation and photocatalytic performance via adding oxygen reduction reaction catalysts into the photocatalysts, Appl. Catal. B Environ. 218 (2017) 174-185. doi:10.1016/j.apcatb.2017.06.030.

[19] W. Wang, Y. Yu, T. An, G. Li, H.Y. Yip, J.C. Yu, P.K. Wong, Visible-light-driven photocatalytic inactivation of E. coli K-12 by bismuth vanadate nanotubes: Bactericidal performance and mechanism, Environ. Sci. Technol. 46 (2012) 4599-4606. doi:10.1021/es2042977. 
[20] N. Muhd Julkapli, S. Bagheri, S. Bee Abd Hamid, Recent advances in heterogeneous photocatalytic decolorization of synthetic dyes, Sci. World J. 2014 (2014). doi:10.1155/2014/692307.

[21] A. Fujishima, T.N. Rao, D.A. Tryk, Titanium dioxide photocatalysis, J. Photochem. Photobiol. C Photochem. Rev. 1 (2000) 1-21. doi:10.1016/S1389-5567(00)00002-2.

[22] K.I. Hadjiivanov, D.G. Klissurski, Surface chemistry of titania (anatase) and titaniasupported catalysts, Chem. Soc. Rev. 25 (1996) 61. doi:10.1039/cs9962500061.

[23] D. Friedmann, C. Mendive, D. Bahnemann, TiO2for water treatment: Parameters affecting the kinetics and mechanisms of photocatalysis, Appl. Catal. B Environ. 99 (2010) 398-406. doi:10.1016/j.apcatb.2010.05.014.

[24] T. Salthammer, S. Mentese, R. Marutzky, Formaldehyde in the indoor environment, Chem. Rev. 110 (2010) 2536-2572. doi:10.1021/cr800399g.

[25] J.C. Yu, L. Zhang, Z. Zheng, J. Zhao, Synthesis and characterization of phosphated mesoporous titanium dioxide with high photocatalytic activity, Chem. Mater. 15 (2003) 2280-2286. doi:10.1021/cm0340781.

[26] S.B. Kim, S.C. Hong, Kinetic study for photocatalytic degradation of volatile organic compounds in air using thin film TiO2photocatalyst, Appl. Catal. B Environ. 35 (2002) 305-315. doi:10.1016/S0926-3373(01)00274-0.

[27] X.Z. Li, F.B. Li, Study of Au/Au3+-TiO2 photocatalysts toward visible photooxidation for water and wastewater treatment, Environ. Sci. Technol. 35 (2001) 2381-2387. doi:10.1021/es001752w.

[28] A. Kumar, V. Sharma, S. Kumar, A. Kumar, V. Krishnan, Towards utilization of full solar light spectrum using green plasmonic $\mathrm{Au}-\mathrm{TiOxphotocatalyst} \mathrm{at} \mathrm{ambient} \mathrm{conditions,}$ Surfaces and Interfaces. 11 (2018) 98-106. doi:10.1016/j.surfin.2018.03.005.

[29] Y. Zheng, L. Zheng, Y. Zhan, X. Lin, Q. Zheng, K. Wei, Ag/ZnO heterostructure nanocrystals: Synthesis, characterization, and photocatalysis, Inorg. Chem. 46 (2007) 69806986. doi:10.1021/ic700688f.

[30] X. Zhang, Y. Wang, B. Liu, Y. Sang, H. Liu, Heterostructures construction on TiO2nanobelts: A powerful tool for building high-performance photocatalysts, Appl. Catal. B Environ. 202 (2017) 620-641. doi:10.1016/j.apcatb.2016.09.068.

[31] Y. Wang, Q. Wang, X. Zhan, F. Wang, M. Safdar, J. He, Visible light driven type II 
heterostructures and their enhanced photocatalysis properties: A review, Nanoscale. 5 (2013) 8326-8339. doi:10.1039/c3nr01577g.

[32] R. Wang, G. Jiang, Y. Ding, Y. Wang, X. Sun, X. Wang, W. Chen, Photocatalytic activity of heterostructures based on $\mathrm{TiO} 2$ and halloysite nanotubes, ACS Appl. Mater. Interfaces. 3 (2011) 4154-4158. doi:10.1021/am201020q.

[33] H. McDaniel, P.E. Heil, C.L. Tsai, K. Kim, M. Shim, Integration of type II nanorod heterostructures into photovoltaics, ACS Nano. 5 (2011) 7677-7683. doi:10.1021/nn2029988.

[34] D.C. Lee, I. Robel, J.M. Pietryga, V.I. Klimov, Infrared-active heterostructured nanocrystals with ultralong carrier lifetimes, J. Am. Chem. Soc. 132 (2010) 9960-9962. doi:10.1021/ja102716p.

[35] C.J. Dooley, S.D. Dimitrov, T. Fiebig, Ultrafast electron transfer dynamics in CdSe/CdTe donor-acceptor nanorods, J. Phys. Chem. C. 112 (2008) 12074-12076. doi:10.1021/jp804040r.

[36] G.D. Scholes, M. Jones, S. Kumar, Energetics of photoinduced electron-transfer reactions decided by quantum confinement, J. Phys. Chem. C. 111 (2007) 13777-13785. doi:10.1021/jp0754583.

[37] Z. Jiang, K. Qian, C. Zhu, H. Sun, W. Wan, J. Xie, H. Li, P.K. Wong, S. Yuan, Carbon nitride coupled with CdS-TiO2nanodots as 2D/0D ternary composite with enhanced photocatalytic H2evolution: A novel efficient three-level electron transfer process, Appl. Catal. B Environ. 210 (2017) 194-204. doi:10.1016/j.apcatb.2017.03.069.

[38] X. Zeng, T. Zhou, C. Leng, Z. Zang, M. Wang, W. Hu, X. Tang, S. Lu, L. Fang, M. Zhou, Performance improvement of perovskite solar cells by employing a CdSe quantum dot/PCBM composite as an electron transport layer, J. Mater. Chem. A. 5 (2017) 17499_ 17505. doi:10.1039/c7ta00203c.

[39] Y. Huanping, Zhou; Qi, Chen; Gang, Li; Song Luo; Tze-bing, Song; Hsin-Sheng, Duan; Ziruo, Hong; Jingbi, You; Yongsheng, Liu; Yang, Interface engineering of highly efficient perovskite solar cells, Science (80-. ). 345 (2014) 542-546. doi:10.1126/science.1254050.

[40] C. Cuhadar, S.G. Kim, J.M. Yang, J.Y. Seo, D. Lee, N.G. Park, All-Inorganic Bismuth Halide Perovskite-like Materials A3Bi2I9 and A3Bi1.8Na0.2I8.6 ( $\mathrm{A}=\mathrm{Rb}$ and $\mathrm{Cs}$ ) for LowVoltage Switching Resistive Memory, ACS Appl. Mater. Interfaces. 10 (2018) 29741- 
29749. doi:10.1021/acsami.8b07103.

[41] A.J. Lehner, D.H. Fabini, H.A. Evans, C.A. Hébert, S.R. Smock, J. Hu, H. Wang, J.W. Zwanziger, M.L. Chabinyc, R. Seshadri, Crystal and Electronic Structures of Complex Bismuth Iodides A3Bi2I9(A = K, Rb, Cs) Related to Perovskite: Aiding the Rational Design of Photovoltaics, Chem. Mater. $27 \quad$ (2015) 7137-7148. doi:10.1021/acs.chemmater.5b03147.

[42] N.G. Park, Perovskite solar cells: An emerging photovoltaic technology, Mater. Today. 18 (2015) 65-72. doi:10.1016/j.mattod.2014.07.007.

[43] S. Heo, G. Seo, Y. Lee, D. Lee, M. Seol, J. Lee, J.-B. Park, K. Kim, D.-J. Yun, Y.S. Kim, J.K. Shin, T.K. Ahn, M.K. Nazeeruddin, Deep level trapped defect analysis in $\mathrm{CH} 3 \mathrm{NH} 3 \mathrm{PbI} 3$ perovskite solar cells by deep level transient spectroscopy, Energy Environ. Sci. 10 (2017) 1128-1133. doi:10.1039/C7EE00303J.

[44] R.L.Z. Hoye, R.E. Brandt, A. Osherov, V. Stevanovic, S.D. Stranks, M.W.B. Wilson, H. Kim, A.J. Akey, J.D. Perkins, R.C. Kurchin, J.R. Poindexter, E.N. Wang, M.G. Bawendi, V. Bulovic, T. Buonassisi, Methylammonium Bismuth Iodide as a Lead-Free, Stable Hybrid Organic-Inorganic Solar Absorber, Chem. - A Eur. J. 22 (2016) 2605-2610. doi:10.1002/chem.201505055.

[45] A.H. Slavney, T. Hu, A.M. Lindenberg, H.I. Karunadasa, A Bismuth-Halide Double Perovskite with Long Carrier Recombination Lifetime for Photovoltaic Applications, J. Am. Chem. Soc. 138 (2016) 2138-2141. doi:10.1021/jacs.5b13294.

[46] S. V. Mel'nikova, a. I. Zaitsev, Ferroelectric phase transition in Cs3Bi2I9, Phys. Solid State. 39 (1997) 1652-1654. doi:10.1134/1.1129882.

[47] O. Lindqvist, G. Johansson, F. Sandberg, T. Norin, The Crystal Structure of Cesium Bismuth Iodide, Cs3Bi2I9., Acta Chem. Scand. 22 (1968) 2943-2952. doi:10.3891/acta.chem.scand.22-2943.

[48] I.P. Aleksandrov, A.F. Bovina, O.A. Ageev, A.A. Sukhovskii, Incommensurate phase in the layered hexagonal crystal Cs3Bi2I9, Phys. Solid State. 39 (1997) 991-994. doi:10.1134/1.1130118.

[49] G.E. Eperon, S.D. Stranks, C. Menelaou, M.B. Johnston, L.M. Herz, H.J. Snaith, Formamidinium lead trihalide: A broadly tunable perovskite for efficient planar heterojunction solar cells, Energy Environ. Sci. $7 \quad$ (2014) 982-988. 
doi:10.1039/c3ee43822h.

[50] N.K. Noel, S.D. Stranks, A. Abate, C. Wehrenfennig, S. Guarnera, A.A. Haghighirad, A. Sadhanala, G.E. Eperon, S.K. Pathak, M.B. Johnston, A. Petrozza, L.M. Herz, H.J. Snaith, Lead-free organic-inorganic tin halide perovskites for photovoltaic applications, Energy Environ. Sci. 7 (2014) 3061-3068. doi:10.1039/c4ee01076k.

[51] B. Lee, C.C. Stoumpos, N. Zhou, F. Hao, C. Malliakas, C.Y. Yeh, T.J. Marks, M.G. Kanatzidis, R.P.H. Chang, Air-stable molecular semiconducting iodosalts for solar cell applications: Cs2SnI6 as a hole conductor, J. Am. Chem. Soc. 136 (2014) 15379-15385. doi:10.1021/ja508464w.

[52] D.W. Bahnemann, Solar Water Detoxification: Novel Ti02 Powders as Highly Active Photocatalysts, 119 (2016).

[53] B.W. Park, B. Philippe, X. Zhang, H. Rensmo, G. Boschloo, E.M.J. Johansson, Bismuth Based Hybrid Perovskites A3Bi2I9 (A: Methylammonium or Cesium) for Solar Cell Application, Adv. Mater. 27 (2015) 6806-6813. doi:10.1002/adma.201501978.

[54] A. Nilă, M. Baibarac, A. Matea, R. Mitran, I. Baltog, Exciton-phonon interactions in the Cs3Bi2I9 crystal structure revealed by Raman spectroscopic studies, Phys. Status Solidi Basic Res. 254 (2017). doi:10.1002/pssb.201552805.

[55] A.A. Ismail, S.A. Al-Sayari, D.W. Bahnemann, Photodeposition of precious metals onto mesoporous $\mathrm{TiO} 2$ nanocrystals with enhanced their photocatalytic activity for methanol oxidation, Catal. Today. 209 (2013) 2-7. doi:10.1016/j.cattod.2012.09.027.

[56] T. Nash, The Colorimetric Estimation of Formaldehyde by Means of the Hantzsch Reaction, Nature. 170 (1952) 976-977.

[57] Y. Son, V. Mishin, W. Welsh, S.E. Lu, J.D. Laskin, H. Kipen, Q. Meng, A novel highthroughput approach to measure hydroxyl radicals induced by airborne particulate matter, Int. J. Environ. Res. Public Health. 12 (2015) 13678-13695. doi:10.3390/ijerph121113678.

[58] W. Li, R. Liang, A. Hu, Z. Huang, Y.N. Zhou, Generation of oxygen vacancies in visible light activated one-dimensional iodine TiO2photocatalysts, RSC Adv. 4 (2014) 36959_ 36966. doi:10.1039/c4ra04768k.

[59] J. Pal, A. Bhunia, S. Chakraborty, S. Manna, S. Das, A. Dewan, S. Datta, A. Nag, Synthesis and Optical Properties of Colloidal M3Bi2I9 (M=Cs, Rb) Perovskite Nanocrystals, J. Phys. Chem. C. 122 (2018) acs.jpcc.8b03542. doi:10.1021/acs.jpcc.8b03542. 
[60] G.M. Paternò, N. Mishra, A.J. Barker, Z. Dang, G. Lanzani, L. Manna, A. Petrozza, Broadband Defects Emission and Enhanced Ligand Raman Scattering in 0D Cs3Bi2I9 Colloidal Nanocrystals, Adv. Funct. Mater. 29 (2019) 0-19. doi:10.1002/adfm.201805299.

[61] M. Miyauchi, H. Irie, M. Liu, X. Qiu, H. Yu, K. Sunada, K. Hashimoto, Visible-LightSensitive Photocatalysts: Nanocluster-Grafted Titanium Dioxide for Indoor Environmental Remediation, J. Phys. Chem. Lett. 7 (2016) 75-84. doi:10.1021/acs.jpclett.5b02041.

[62] F. Gao, Y. Yang, T. Wang, Preparation of porous TiO2/Ag heterostructure films with enhanced photocatalytic activity, Chem. Eng. J. $270 \quad$ (2015) 418-427. doi:10.1016/j.cej.2015.02.048.

[63] F. Bai, Y. Hu, Y. Hu, T. Qiu, X. Miao, S. Zhang, Lead-free, air-stable ultrathin Cs3Bi2I9perovskite nanosheets for solar cells, Sol. Energy Mater. Sol. Cells. 184 (2018) 15-21. doi:10.1016/j.solmat.2018.04.032.

[64] J.A. Colon, G.; Hidalgo, M.C.; Navio, Photocatalytic deactivation of commercial TiO2 samples during simultaneous photoreduction of $\mathrm{Cr}(\mathrm{VI})$ and photooxidation of salicylic acid, J. Photochem. Photobiol. A Chem. 138 (2001) 79-85.

[65] F. Ungureanu, R. Medianu, R. V Ghita, C.C. Negrila, P. Ghita, A.S. Manea, M.F. Lazarescu, P.O.B. Mg-, Properties of TiO 2 thin films prepared by different techniques, 9 (2007) 14571461.

[66] H. Yan, X. Wang, M. Yao, X. Yao, Band structure design of semiconductors for enhanced photocatalytic activity: The case of TiO2, Prog. Nat. Sci. Mater. Int. 23 (2013) 402-407. doi:10.1016/j.pnsc.2013.06.002.

[67] K. Sayama, H. Arakawa, Photocatalytic decomposition of water and photocatalytic reduction of carbon dioxide over zirconia catalyst, J. Phys. Chem. 97 (1993) 531-533. doi:10.1021/j100105a001.

[68] W.P. Cardon, F.; Gomes, On the determination of the flat-band potential of a semiconductor in contact with a metal or an electrolyte from the Mott-Schottky plot, J. Phys. D Appl. Phys. 11 (1978) 63-67.

[69] Y. Nosaka, A.Y. Nosaka, Reconsideration of Intrinsic Band Alignments within Anatase and Rutile TiO2, J. Phys. Chem. Lett. 7 (2016) 431-434. doi:10.1021/acs.jpclett.5b02804.

[70] W. Zhang, Z. Chen, S. Li, Dye-sensitized solar cells based on Bi4Ti3O 12, Int. J. Photoenergy. 2011 (2011) 3-8. doi:10.1155/2011/821045. 
[71] R. Beranek, (Photo)electrochemical methods for the determination of the band edge positions of TiO 2-based nanomaterials, Adv. Phys. Chem. 2011 (2011). doi:10.1155/2011/786759.

[72] O. Ola, M.M. Maroto-Valer, Review of material design and reactor engineering on $\mathrm{TiO}<$ inf $>2</$ inf $>$ photocatalysis for $\mathrm{CO}<$ inf $>2</$ inf $>$ reduction, J. Photochem. Photobiol. C Photochem. Rev. 24 (2015) 16-42. doi:10.1016/j.jphotochemrev.2015.06.001.

[73] J.R. Guimarães, C.R. Turato Farah, M.G. Maniero, P.S. Fadini, Degradation of formaldehyde by advanced oxidation processes, J. Environ. Manage. 107 (2012) 96-101. doi:10.1016/j.jenvman.2012.04.024.

[74] X. Fang, G. Mark, C. Von Sonntag, OH radical formation by ultrasound in aqueous solutions: Part I: The chemistry underlying the terephthalate dosimeter, Ultrason. Sonochem. 3 (1996) 57-63. doi:10.1016/1350-4177(95)00032-1.

[75] D.H. Gonzalez, X.M. Kuang, J.A. Scott, G.O. Rocha, S.E. Paulson, Terephthalate Probe for Hydroxyl Radicals: Yield of 2-Hydroxyterephthalic Acid and Transition Metal Interference, Anal. Lett. 51 (2018) 1-10. doi:10.1080/00032719.2018.1431246.

[76] M. Sahni, B.R. Locke, Quantification of hydroxyl radicals produced in aqueous phase pulsed electrical discharge reactors, Ind. Eng. Chem. Res. 45 (2006) 5819-5825. doi:10.1021/ie0601504. 